\title{
Estratégias didático-metodológicas para o uso de software educativos gratuitos na educação matemática
}

\author{
Didactic-methodological strategies for the use with \\ free educational software in mathematical education
}

\author{
ALEANDRA DA SILVA FIGUEIRA-SAMPAIO \\ Universidade Federal de Uberlândia (FAGEN) \\ ELIANE ELIAS FERREIRA DOS SANTOS \\ Universidade Federal de Uberlândia (ESEBA) \\ GILBERTO ARANTES CARRIJO \\ Universidade Federal de Uberlândia (FEELT) \\ QUINTILIANO SIQUEIRA SCHRODEN NOMELINI \\ Universidade Federal de Uberlândia (FAMAT)
}

\begin{abstract}
Resumo: Há muitas dúvidas quanto ao uso de recursos digitais no ensino de matemática. É preciso escolher o software adequado aos conteúdos e aos propósitos de ensino. $O$ objetivo deste trabalho foi elaborar estratégias didático-metodológicas para o uso de software gratuitos no ensino de Matemática ( $6^{\circ}$ ao 90 ano), assim como validá-las. As estratégias foram elaboradas conjuntamente com professores que as aplicaram com seus alunos. Duas turmas resolveram os mesmos exercícios em 4 diferentes situações avaliativas para a estratégia validada. O percentual de acertos foi analisado pelo teste Kruskal Wallis. Cinco softwares para conteúdos problemáticos do ponto de vista docente, identificados pelos professores de matemática, e três das etapas da Teoria dos Modelos Genéricos, foram considerados na elaboração de 19 estratégias. Dentre as 11 estratégias validadas, pode-se afirmar que a maioria foi favorável ao aprendizado do aluno. Principalmente, quando as estratégias são inseridas após o conteúdo ser trabalhado em sala de aula.
\end{abstract}

Palavras-chave: Estratégias didáticas. Software gratuitos. Ensino de matemática.

Abstract: There are many doubts when it comes to the use of digital resources in the teaching of mathematics. It is necessary first to choose the software that is most adequate in terms of the teaching purposes. The objective herein was thus to produce didactic-methodological strategies for use with free software directed toward teaching mathematics (6th to 9th grade), as well as to validate such strategies. These strategies were created together with teachers, which went on to apply these to their students. Two groups resolved the same exercises in 4 different evaluative situations for the validated strategy. The percentage of hits was analyzed through the Kruskal Wallis test. Five different software proposals for problematic content from the teacher point of view, identified by the mathematics teacher, and three stages from The Generic Models Theory were considered in the creation of 19 strategies. Among the 11 validated strategies, one can affirm that most were favorable to student learning. This was most evident when the strategies are inserted after the presentation of the content in the classroom environment.

Keywords: Didactic strategies. Free software. Teaching of mathematics. 
FIGUEIRA-SAMPAIO, ALEANDRA DA SILVA; SANTOS, ELIANE ELIAS FERREIRA DOS; CARRIJO, GILBERTO ARANTES; NOMELINI, QUINTILIANO SIQUEIRA SCHRODEN. Estratégias didático-metodológicas para o uso de software educativos gratuitos na educação matemática. Informática na Educação: teoria \& prática, Porto Alegre, v. 22, n. 2, p. 13-41, maio/ago. 2019.

\section{Introdução}

Não há dúvidas de que os recursos digitais vêm provocando importantes mudanças na forma de ensinar e aprender. São recursos que transformam o potencial cognitivo do ser humano (TAVARES; FERNANDES; TAVARES, 2017). No entanto, o recurso por si só não tem impacto sobre a aprendizagem, depende de como é utilizado (GROS, 2016). Em contextos da educação com tecnologias digitais, as teorias de aprendizagem continuam descrevendo o perfil de ensino e de aprendizagem de professores e estudantes (RIBAS; VIALI; LAHM, 2016), sendo necessário que as atividades subsidiadas por esses recursos atendam aos princípios elencados nestas teorias. Neste sentido, é preciso que as estratégias valorizem a construção do conhecimento de maneira colaborativa e mais participativa (BRUM; PEREIRA, 2018). Além disso, deve-se refletir também sobre o potencial de comunicação e interatividade disponibilizado nas ferramentas tecnológicas no sentido de que a aprendizagem por meio de recursos virtuais favoreça o exercício cognitivo e o desenvolvimento de novas competências cognitivas (TAVARES; FERNANDES; TAVARES, 2017).

Quanto à disciplina de matemática, a maioria dos alunos apresenta uma reação negativa (VALENTE, 1993; GARDETE; CÉSAR, 2006). Apesar de alguns alunos afirmarem que gostam muito e que têm facilidade na disciplina, chegando a alcançar desempenhos elevados, muitos discentes afirmam que a detestam e que é demasiado difícil, não conseguindo alcançar as competências consideradas necessárias para transitarem de ano (GARDETE; CÉSAR, 2006).

Na tentativa de reverter esta situação, professores de matemática trabalham com práticas docentes diferenciadas e utilizam materiais concretos e manipuláveis para auxiliar no processo de ensino e aprendizagem. No entanto, algumas práticas com materiais concretos apresentam grandes limitações. Por exemplo, no uso da balança de dois pratos para ensinar procedimentos de resolução de equações do $1^{0}$ grau, somente o professor pode manuseá-la de forma a concluir experimento. Além disso, existem problemas sérios em relação ao aferimento da balança. A informática, por meio de computadores e software educativos, pode ser uma alternativa neste processo (FIGUEIRA-SAMPAIO; SANTOS; CARRIJO, 2009). Muitos materiais concretos podem ser substituídos por software, com ganho na atratividade dos alunos e praticidade para os professores. Os softwares podem ainda estimular outras características cognitivas inerentes à concepção construtivista, como cooperação, diálogo, reflexão, colaboração, autonomia, reciprocidade e responsabilidade (MARCHESE, 1997; FIGUEIRASAMPAIO; SANTOS; CARRIJO, 2009).

Para fins conceituais, softwares educativos são recursos digitais desenvolvidos exclusivamente para usos educacionais previstos desde o seu projeto e desenvolvimento (OLIVEIRA; COSTA; MOREIRA, 2001; BASSANI et al., 2006; TCHOUNIKINE, 2011) e que são usados por professores e alunos para apoiar o ensino e a aprendizagem (NATIONAL CENTRE 
FOR TECHNOLOGY IN EDUCATION, 2008), considerando objetivos pedagógicos (TCHOUNIKINE, 2011).

Desde a década de 1980, muitas pesquisas têm sido desenvolvidas com o intuito de investigar o uso da informática e seu impacto no ensino e aprendizagem matemática (BURNS; BOZEMAN, 1981; KULIK; KULIK，1985; COX，1997; SIVIN-KACHALA; BIALO, 2000; CEO FORUM ON EDUCATION AND TECHNOLOGY, 2001; ARTIGUE, 2002; KULIK, 2002; YUSHAU; BOKHARI; WESSELS, 2004; VALENZUELA; GRECCO; SOUZA, 2009; ASSIS; BEZERRA, 2011; LOPES, 2011; LOPES, 2013; GOULART; SILVA, 2015; OLIVEIRA; GONÇALVES, 2018).

Apesar dos alunos não resistirem ao uso das tecnologias (AREIAS; NOBRE; PASSOS, 2017), as escolas encontram certos obstáculos quanto à adoção da informática no ensino de matemática, principalmente relacionado à qualidade e aspecto educativo dos softwares (COLEY; CRADLER; ENGEL, 1997; RAMOS et al., 2005) e a formação dos professores (BORGES, 2008; ZILIO; ALVES, 2013; CHINELLATO; JAVARONI, 2014; ARAÚJO; RIBEIRO JÚNIOR, 2017). Os softwares pela disponibilidade de requisitos e funcionalidades apropriados ao plano docente; e o professor por poder considerar o computador como recurso didático em seu plano de ensino.

Vários softwares educativos gratuitos destinados à educação matemática são desenvolvidos e disponibilizados (FIGUEIRA-SAMPAIO; SANTOS; CARRIJO, 2014; SANTOS; FIGUEIRASAMPAIO; CARRIJO, 2015, 2017). Assim como, pesquisas são realizadas na tentativa de desenvolver sequências ou propostas didáticas vinculadas ao uso de software educativos (LOPES, 2011; LOPES, 2013; GOULART; SILVA, 2015; OLIVEIRA; GONÇALVES, 2018). Mesmo com tantos softwares disponíveis, a quantidade de softwares utilizada por professores de matemática ainda é muita pequena comparada com a utilização de materiais concretos manipuláveis (FIGUEIRA-SAMPAIO et al., 2012a; FIGUEIRA-SAMPAIO et al., 2013).

Do ponto de vista didático-pedagógico, o software educativo é considerado de suma importância no que se entende por ambiente educacional, sendo um componente escolhido pelo professor (GLADCHEFF; OLIVEIRA; SILVA, 2001). O software inadequado não contribui para melhoria e inovação na prática de ensino, e distancia professores e alunos do processo de ensino e aprendizagem (BALANSKAT; BLAMIRE; KEFALA, 2006).

Em relação ao planejamento das atividades, é preciso escolher o software adequado aos conteúdos e aos propósitos de ensino. Que intervenções podem ser realizadas na prática docente de matemática para contribuir com o uso de software educativos? A prática docente relacionada à introdução do conteúdo pode ser iniciada ou não com o uso de softwares educativos no processo de ensino e aprendizagem de matemática? Diante destes questionamentos, o objetivo do trabalho foi elaborar estratégias didático-metodológicas para o uso de softwares educativos gratuitos no ensino de Matemática do $6^{\circ}$ ao $9^{\circ}$ ano, assim como validar a utilização das atividades por professores em diferentes momentos na prática docente de matemática. 


\section{Metodologia}

A pesquisa foi de caráter exploratório e descritivo. Para auxiliar na visão geral acerca do fenômeno em perspectiva e para expor as características desse fenômeno, a pesquisa foi desenvolvida junto a professores de matemática do Ensino Fundamental II (do $6^{\circ}$ ao $9^{\circ}$ ano) e a alunos de escolas públicas em Uberlândia - MG.

A falta de conhecimento do que pode ser feito com um software dificulta a inserção da informática no ensino de Matemática (LOVIS; FRANCO, 2013). Dessa forma, num primeiro momento, em 2014, para a elaboração das estratégias didático-pedagógicas, foram realizadas oficinas quinzenais com os professores de matemática em laboratórios de informática com acesso à internet (Figura 1). Nas oficinas, foram exploradas as funcionalidades e explicadas as interfaces de software educativos gratuitos de matemática para o Ensino Fundamental II, mapeados por Figueira-Sampaio, Santos e Carrijo (2014), Santos, Figueira-Sampaio e Carrijo (2015) e Santos, Figueira-Sampaio e Carrijo (2017).

Após o trabalho com os softwares, os professores elencaram e discutiram (a) os conteúdos de matemática que os alunos encontravam maior dificuldade no processo de aprendizagem; (b) os softwares adequados para a abordagem desses conteúdos; e (c) a estrutura desejável das atividades de ensino a serem desenvolvidas com o uso de recursos digitais.

Com as estratégias didático-pedagógicas elaboradas e finalizadas, os professores receberam orientações quanto ao procedimento no uso dos softwares nas práticas docentes de matemática.

Num segundo momento, em 2015 e 2016, para a validação das estratégias didáticometodológicas, os professores adotaram as estratégias em diferentes momentos na prática docente (Figura 2). O interesse e a participação dos professores nas oficinas determinaram as turmas de alunos e as escolas. O planejamento anual do professor não foi afetado. As aulas foram conduzidas normalmente nas escolas e, quando adequado, o software e a estratégia foram usados no processo de ensino.

Para cada estratégia, as unidades de análise foram 2 diferentes turmas de alunos (Turma $\mathrm{A}$ e B) em 4 situações avaliativas - L, LS, S e SL. A Turma A usou a estratégia no laboratório de informática e resolveu os exercícios na situação avaliativa $L$, depois a turma $A$ teve aula em sala de aula, com o método de ensino do professor, e resolveu os exercícios na situação avaliativa LS. Enquanto que, a Turma B primeiramente viu o conteúdo em sala de aula e resolveu os exercícios na situação avaliativa S; depois a Turma B teve aula no laboratório de informática com a estratégia e resolveu os exercícios na situação avaliativa SL. Nas situações avaliativas, foram resolvidos os mesmos exercícios pelos alunos, sempre na aula de matemática após os professores terem ministrado o conteúdo nas 2 sequências pré-definidas para cada turma (Figura 2). O número de alunos por turma variou de 16 a 111 alunos, com a participação de 11 professores. 
Figura 1 - Esquema para a elaboração das estratégias didático-pedagógicas

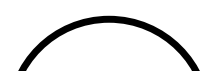

Professores de Matemática

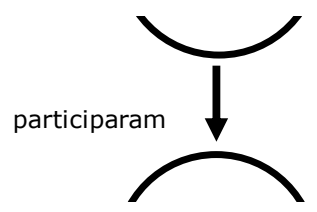

Oficinas

Laboratórios de Informática

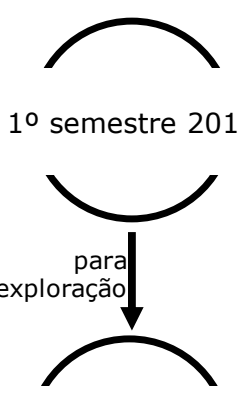

Interface Funcionalidades

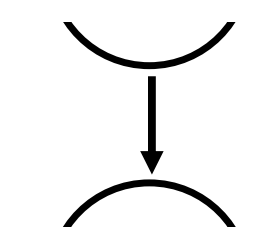

Software Educativos Gratuitos

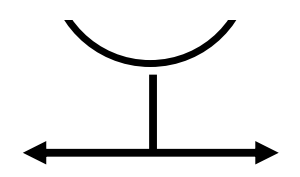

no período

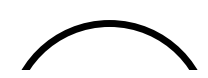

$2^{\circ}$ semestre 2014

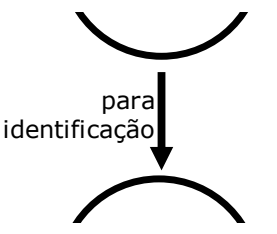

Conteúdos de Matemática

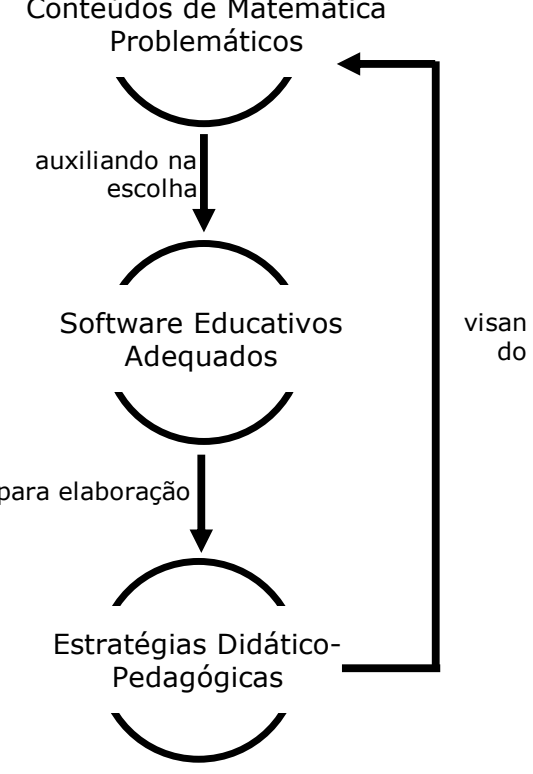

Fonte: Os autores.

Em ambas as turmas, os alunos formaram duplas nos laboratórios de informática, uma vez que, em Figueira-Sampaio, Santos e Carrijo (2009), foi observado que a experiência em dupla criou um ambiente de mediação incentivado pelo trabalho em equipe e pela responsabilidade da dupla em concluir a atividade. Com esta proximidade, os alunos passaram a se comunicar, eles ouviam sugestões ou colocavam novas questões ao companheiro. $O$ trabalho cooperativo despertou nos alunos a preocupação com a aprendizagem do outro. O aluno mais apto serviu 
como orientador direto do aluno menos apto durante a atividade e, até mesmo, quanto ao funcionamento do software educativo.

Para cada estratégia, foram elaborados exercícios para avaliação da aprendizagem. Os exercícios, em folha de papel, consistiam de questões abertas para serem resolvidas individualmente.

Quanto aos critérios de correção, foram criados critérios específicos de correção para cada situação avaliativa considerando conceitos e procedimentos matemáticos envolvidos na estratégia. As indicações de acerto variaram de 0 a 100\%, sendo 0 para resoluções incorretas ou não resolvidas e 100 para resoluções e respostas totalmente corretas. Para as resoluções parcialmente corretas, mesmo com partes incorretas ou incompletas, foram atribuídas notas proporcionais à relevância da parte resolvida de forma correta pelo aluno.

Figura 2 - Esquema para a validação das estratégias didático-metodológicas

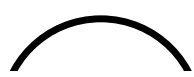

Estratégia Didático-Metodológica

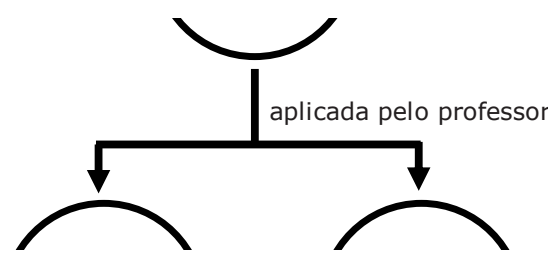

Turma A

Turma B
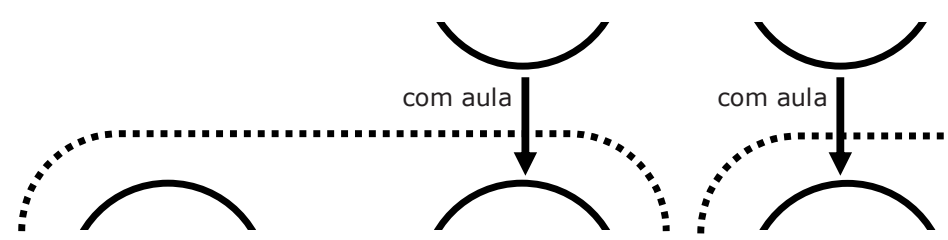

Situação Avaliativa L

Laboratório de

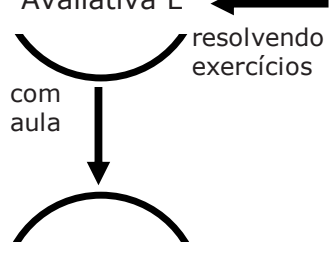

Informática

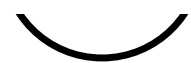

Sala de Aula

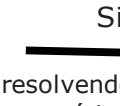

Situação Avaliativa

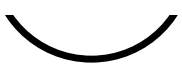
exercícios
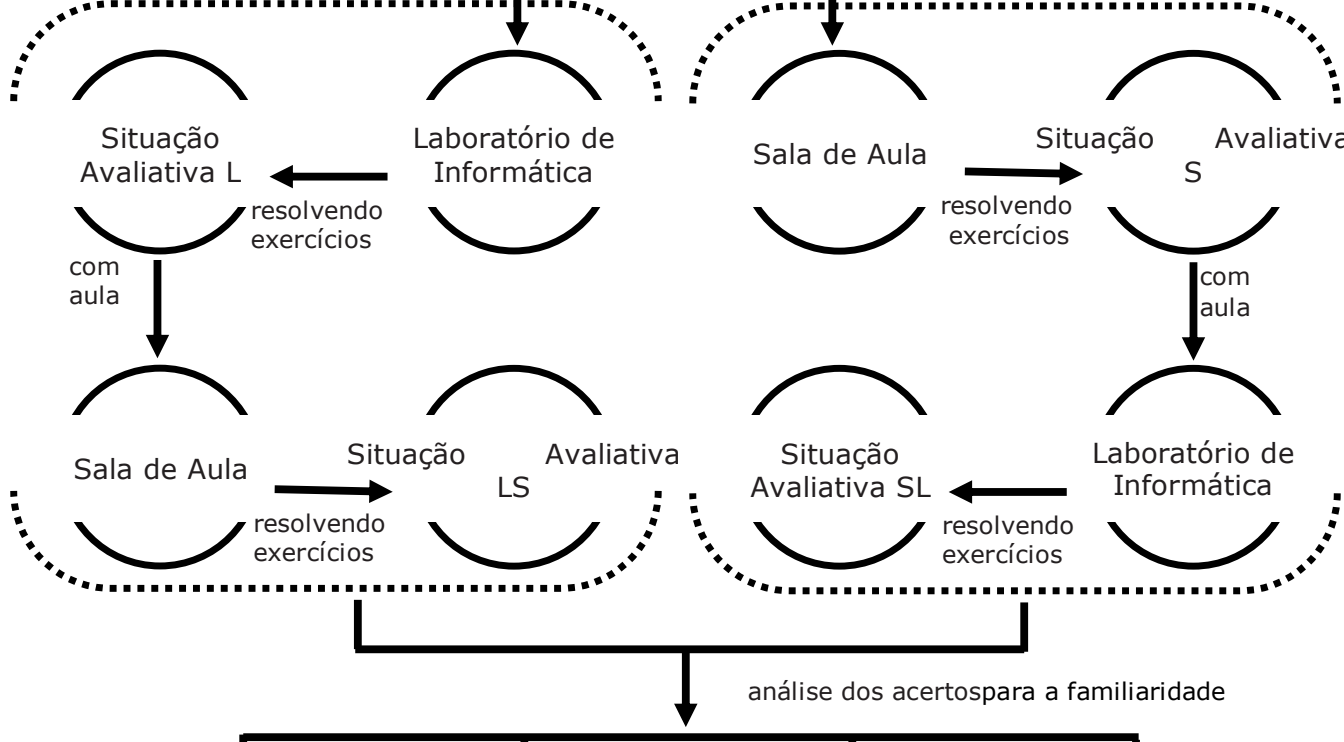

Situação

Avaliativa SL

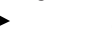

S
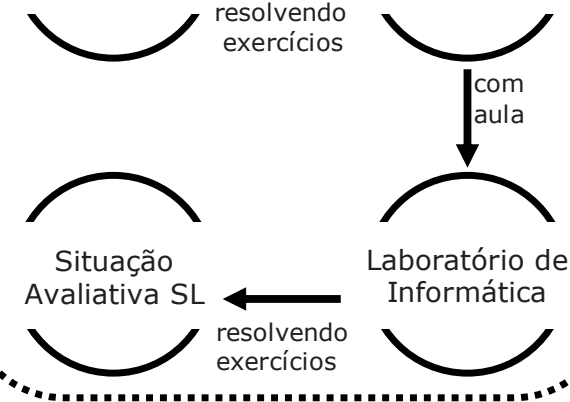

resolvendo

Laboratório de Informática

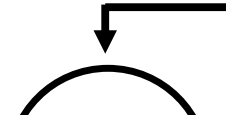

Turma A

$\mathrm{L}$

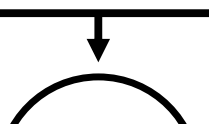

Turma A

LS

análise dos acertospara a familiaridade

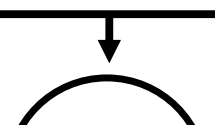

Turma B

$\mathrm{S}$

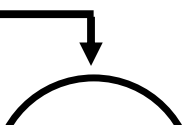

Turma B

SL 
Fonte: Os autores.

No processo de análise dos dados, para comparar o percentual de acertos nas diferentes situações avaliativas, em função da sequência de aula, depois de realizar um estudo de análise de variância (ANAVA) de um delineamento inteiramente casualizado e observar que os resíduos não atenderam às pressuposições de normalidade e homogeneidade das variâncias, foi aplicado o teste não-paramétrico de Kruskal Wallis, considerando significativo valor de $p<0,05$, e os percentuais de acertos foram representados pela mediana devido à assimetria dos dados. As análises foram realizadas utilizando o ambiente R (R DEVELOPMENT CORE TEAM, 2011).

\section{Resultados e discussão}

\subsection{Elaboração das estratégias didático-metodológicas para software educativos gratuitos de matemática}

Os professores identificaram cinco softwares com potenciais imediatos para auxiliar em conteúdos de matemática considerados problemáticos do ponto de vista docente. Ao todo, foram elaboradas dezenove estratégias didático-metodológicas para a utilização de recursos digitais nas práticas docentes de matemática, sendo cinco estratégias para o software Criba de Eratóstenes ${ }^{1}$ (Estratégias 1, 2, 3, 4 e 5), duas para o Fracciones Equivalentes ${ }^{1}$ (Estratégias 6 e 7), sete para o GeoGebra ${ }^{1}$ (Estratégias 8, 9, 10, 11, 12, 13 e 14), quatro para o software MathGV ${ }^{1}$ (Estratégias 15, 16, 17 e 18) e uma estratégia para o Poly ${ }^{1}$ (Estratégia 19) (Tabela 1).

Diante das discussões e troca de ideias entre os professores, optou-se pelo desenvolvimento de estratégias didático-metodológicas padronizadas sequencialmente e que os alunos pudessem realizar determinados registros durante a atividade. As estratégias, como planos de aula, deveriam representar um roteiro de orientação para a utilização dos softwares junto aos alunos e para que se pudessem atingir um objetivo ao final de cada atividade. Dessa forma, as estratégias foram organizadas com a identificação do software, o conteúdo matemático a ser abordado, o objetivo a ser alcançado ao final da atividade e os procedimentos sequenciais para o aluno seguir durante a aula.

Quando se trata da elaboração de materiais didáticos que utilizam recursos digitais é necessário garantir a existência de uma identidade visual e estrutural para os materiais, de modo que o estudante se sinta seguro ao lidar com elementos já conhecidos ao longo da atividade (CAVELLUCCI et al., 2013). Assim, nas estratégias optou-se pela presença de ícones, para alertar os alunos quanto ao cumprimento de um procedimento específico. Também se intercalou ilustrações do software com textos para conduzir o aluno no desenvolvimento da

\footnotetext{
${ }^{1}$ www.webmath.online
} 
atividade. Na construção da identidade visual, foram criados três ícones exclusivos quanto às ações dos alunos nos procedimentos propostos.

O ícone Lápis indica que o aluno precisa registrar as respostas de questionamentos à medida em que ele avança na atividade. Os registros escritos, simbólicos e as representações icônicas constituem uma forma de comunicação que tem um papel importante no ensino e na aprendizagem da Matemática. Segundo Ponte et al. (2007), ao escrever e ao falar sobre a Matemática é que os alunos desenvolvem a capacidade de comunicação matemática. É assim que os alunos refletem sobre a compreensão da Matemática, fazem conexões e aprendem os conceitos matemáticos. As questões apresentadas na atividade permitem que o professor dirija o discurso, mantenha um controle do processo de comunicação e, ao mesmo tempo, mantenha o aluno focado no software, diminuindo a navegação por outras páginas e sites da internet. Em geral, as perguntas induzem a respostas imediatas e únicas e direcionam a atenção do aluno para o que foi observado, considerando o conceito a ser construído, a partir da sua interação com o software.

A Lupa está associada com a necessidade de observar o que acontece na tela ou no software após ou durante um procedimento. A observação do resultado de suas ações faz com que $o$ aluno não se perca durante a atividade e permite que ele saiba se as ações foram corretas ou não.

A comunicação estabelecida na sala de aula é centrada no diálogo entre o professor e os alunos. Segundo Ponte et al. (2007, p. 42), "a preocupação do professor é tornar as mensagens emitidas compreensíveis aos alunos, eliminando eventuais interferências ou ruídos". Para este fim, criou-se o ícone Quadro onde há uma ou mais informações sobre conceitos, terminologias, síntese do conteúdo ou qualquer informação relevante que o aluno deve ler atentamente antes de prosseguir na atividade.

Tabela 1 - Software educativo gratuito e objetivo das estratégias didático-metodológicas elaboradas para a prática docente de matemática

\begin{tabular}{|c|c|c|}
\hline Software & $\begin{array}{l}\text { Estratégia } \\
\text { no }^{0}\end{array}$ & Objetivo \\
\hline \multirow{5}{*}{$\begin{array}{l}\text { Criba de } \\
\text { Eratóstenes }\end{array}$} & 1 & $\begin{array}{l}\text { Caracterizar números pares/múltiplos de } 2 \text { e números ímpares por meio } \\
\text { das regularidades apresentadas nas respectivas sequências numéricas }\end{array}$ \\
\hline & 2 & Construir o critério de divisibilidade por 3 \\
\hline & 3 & Construir o critério de divisibilidade por 5 \\
\hline & 4 & Construir o conceito de números primos \\
\hline & 5 & $\begin{array}{l}\text { Calcular o mínimo múltiplo comum pela intersecção do conjunto dos } \\
\text { múltiplos }\end{array}$ \\
\hline $\begin{array}{l}\text { Fracciones } \\
\text { Equivalentes }\end{array}$ & 6 & $\begin{array}{l}\text { Identificar uma fração pela sua representação geométrica e numérica; } \\
\text { Reconhecer numerador e denominador. }\end{array}$ \\
\hline
\end{tabular}




\begin{tabular}{|c|c|c|}
\hline \multirow{6}{*}{ GeoGebra } & 8 & $\begin{array}{l}\text { Deduzir expressões para o cálculo da área de superfícies limitadas por } \\
\text { retângulos e quadrados }\end{array}$ \\
\hline & 9 & $\begin{array}{l}\text { Deduzir a expressão para o cálculo da área de superfícies limitadas por } \\
\text { paralelogramos }\end{array}$ \\
\hline & 10 & $\begin{array}{l}\text { Deduzir a expressão para o cálculo da área de superfícies limitadas por } \\
\text { triângulos }\end{array}$ \\
\hline & 11 & $\begin{array}{l}\text { Deduzir expressões para o cálculo da área de superfícies limitadas por } \\
\text { trapézios }\end{array}$ \\
\hline & 13 & Localizar pontos na reta numérica e no plano cartesiano \\
\hline & 14 & Reconhecer os quadrantes do plano cartesiano \\
\hline \multirow{2}{*}{ MathGV } & 15 & $\begin{array}{l}\text { Construir procedimentos para realizar a adição algébrica com números } \\
\text { inteiros de mesmo sinal }\end{array}$ \\
\hline & 16 & $\begin{array}{l}\text { Construir procedimentos para realizar a adição algébrica com números } \\
\text { inteiros de sinais contrários }\end{array}$ \\
\hline Poly & 19 & $\begin{array}{l}\text { Visualizar poliedros em 3D e na sua forma planificada (2D); Identificar e } \\
\text { contar os elementos de um poliedro: vértices, faces e arestas }\end{array}$ \\
\hline
\end{tabular}

Fonte: Os autores.

É importante lembrar que as estratégias foram elaboradas para o professor no papel de mediador da turma, uma vez que Batista, Barcelos e Afonso (2005) alegam que os professores adquirem conhecimento com a utilização dos recursos tecnológicos, não sendo necessário dominá-los para inseri-los na prática docente.

Além da proposta dos ícones, as estratégias também foram elaboradas considerando a Teoria dos Modelos Genéricos (HEJNÝ, 2011, 2012) que identifica cinco etapas no processo de obtenção do conhecimento (Figura 3).

O início deste processo é a motivação, caracterizada pela alegria do sucesso intelectual que vem depois de resolver um problema ou mesmo pela descoberta de uma nova verdade. A etapa dos modelos isolados refere-se a um conjunto de atividades específicas realizadas concretamente. Na etapa seguinte, no modelo genérico, os alunos são orientados a criarem padrões e esquemas gerais a partir de um conjunto de atividades específicas que foram desenvolvidas na etapa anterior, mas ainda assim considerada concreta. Nesta etapa, as atividades isoladas são analisadas em conjunto pela busca de um padrão que as caracteriza.

Do conhecimento generalizado parte-se para o nível de abstração onde a solução do problema ou da atividade independe de aparatos concretos. Na etapa do conhecimento 
abstrato, o aluno cria modelos mentais que the permitem solucionar o problema. A etapa de cristalização constitui a parte permanente deste processo de construção do conhecimento, relaciona-se com a possibilidade de integração de novos conhecimentos.

Figura 3 - Processo de obtenção de conhecimento da Teoria dos Modelos Genéricos

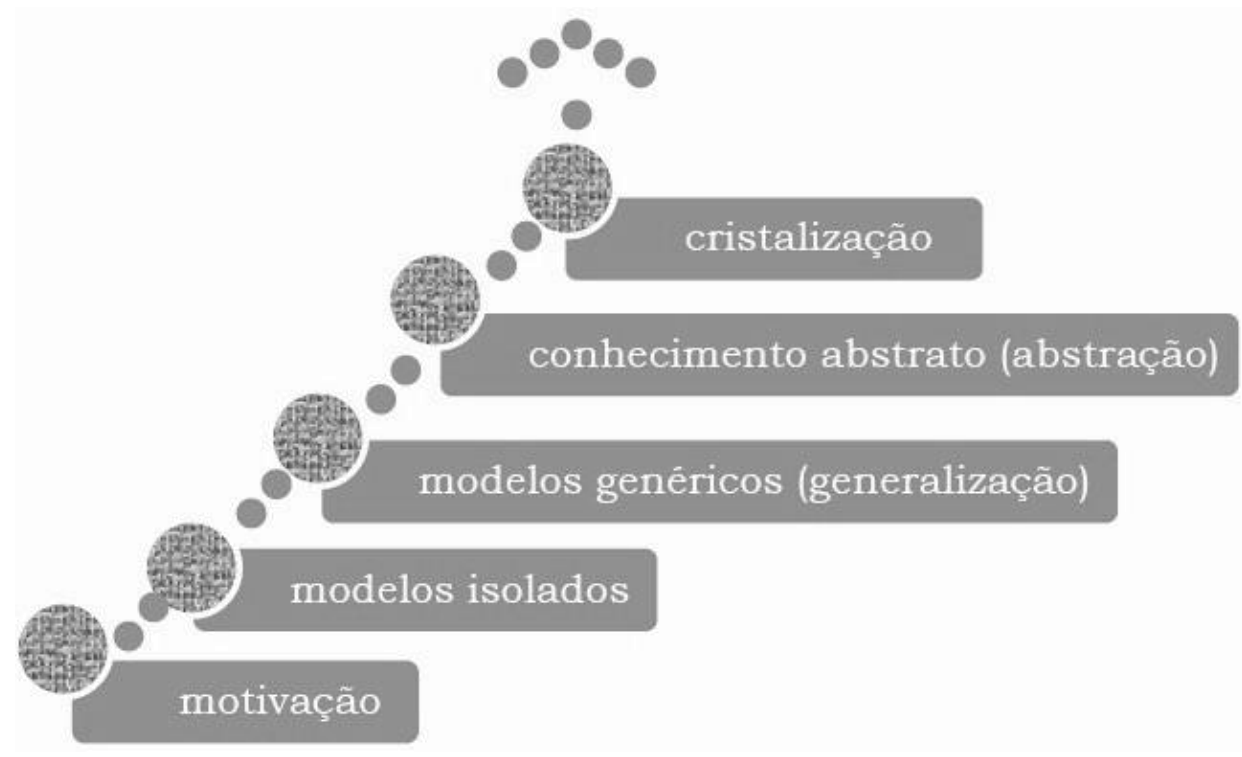

Fonte: Adaptado de Hejný (2011, 2012).

Para a elaboração das estratégias didático-metodológicas cumpriu-se apenas as três primeiras etapas da Teoria dos Modelos Genéricos, consideradas por Hejný (2012) como essenciais para o Ensino Fundamental.

No Ensino Fundamental, os alunos estão acostumados a utilizar os recursos digitais de forma ostensiva. Assim, a utilização desses recursos aproxima as atividades escolares e não escolares. Isso, por si só, garante a motivação dos alunos para a realização das tarefas propostas.

A interação do aluno com o software permite que os objetos virtuais sejam manipulados de forma análoga a que se manipulam os objetos concretos. Este tipo de interação é necessário para a construção dos modelos isolados que são propostos em cada estratégia.

Por fim, para a etapa de generalização, os alunos são orientados a observarem os resultados das atividades isoladas, bem como sua imagem na tela do computador. A análise conjunta desses requisitos tem como objetivo encontrar um padrão que as caracterize. A partir deste padrão, constrói-se um conhecimento novo, uma regra, um conceito ou um procedimento.

A contribuição para uma aprendizagem mecânica, em que o aluno decora o resultado, surge ao desconsiderar as duas etapas que antecedem a etapa de generalização, fornecendo ao aluno 
o resultado pronto. Ele poderá até utilizar o resultado para solucionar alguns problemas, entretanto, se o aluno esquecer o que Ihe foi transmitido não tem como recuperar a informação perdida (HEJNÝ, 2012).

Portanto, as estratégias propostas foram organizadas para ajudar os alunos a perceberem regularidades e construírem generalizações. O suporte para o desenvolvimento do discurso, da argumentação propriamente dita é explícito à medida em que se solicitam justificativas a partir de ações e de observações de regularidades durante a atividade.

As justificativas fazem parte da argumentação matemática e, às vezes, os alunos baseiam suas afirmações em generalizações ou padrões que eles percebem (RUMSEY; LANGRALL, 2016).

Neste sentido, os alunos precisam de apoio para desenvolver o discurso da argumentação matemática. Além do que, na utilização de recursos digitais, Way (2011) considera que, quando a causa e o efeito são observáveis, é oportuno incentivar os alunos a escreverem ou falarem sobre eles.

\subsubsection{As estratégias didático-metodológicas para o software Criba de Eratóstenes}

A teoria dos números é o ramo da matemática pura relacionado com as propriedades, representações e interações entre os números (CURTIS; TULARAM, 2011). A compreensão de aspectos elementares dessa teoria é essencial em todos os níveis de ensino. No nível fundamental, a expectativa é que os alunos utilizem os conceitos de números pares e ímpares, divisibilidade, regras de divisibilidade, fator, números primos, números compostos, fatoração primária, múltiplo, divisível, máximo divisor comum, mínimo múltiplo comum para resolver problemas (NATIONAL COUNCIL OF TEACHERS OF MATHEMATICS - NCTM, 2000).

Dentre esses conceitos, o de número primo desperta um interesse especial. São números considerados blocos construtores de números (ZAZKIS; LILJEDAHL, 2004, CURTIS; TULARAM, 2011), isto significa que é possível obter qualquer número inteiro a partir de um produto de números primos. De fato, o Teorema Fundamental da Aritmética garante que a decomposição de um dado número em fatores primos existe e é única (KURZ; GARCIA, 2012).

Portanto, é importante saber como obter números primos. O crivo de Eratóstenes, formulado em torno de 240 a.C., é uma abordagem simples para gerar números primos no intervalo de $[2, n]$, para $n \in \mathbb{N}$ (CHAKRABARTY; PURKAYASTHA, 2010). O fato de não utilizar fórmulas torna o processo adequado para o trabalho com números primos no ensino fundamental. O crivo é metaforicamente uma peneira, que separa os números primos dos compostos por meio de um processo iterativo que elimina os múltiplos de um número primo. É justamente a ideia da estratégia 4 para a construção do conceito de números primos.

Para todas as estratégias didático-metodológicas que utilizam o software Criba de Eratóstenes, pode-se determinar a quantidade $(n \in \mathbb{N})$ de números naturais a ser exibida na tela do computador. Para melhor explorar o software, as atividades se iniciam com $n=5$ exibindo números de 2 a 50. À medida em que o aluno avança na atividade aumenta-se o 
intervalo como $n=20$, exibindo os números naturais de 2 a 200 e fazendo com que o aluno use a barra de rolagem para a visualização dos números.

Além do trabalho com os números primos, as funcionalidades de "Quitar múltiplos" e "Mostrar múltiplos" do software foram utilizadas para abordar os conteúdos de números pares e ímpares, os critérios de divisibilidade por 3 e por 5 e o cálculo do mínimo múltiplo comum pela intersecção do conjunto dos múltiplos.

A criança, desde pequena, já possui a habilidade de distinguir entre número par ou ímpar. Entretanto, muitas vezes não basta reconhecer que um determinado conjunto apresenta uma determinada propriedade. Para a manipulação de elementos desse conjunto é necessário que exista uma representação da propriedade (ZAZKIS; LILJEDAHL, 2004).

Desta forma, o objetivo na Estratégia 1 foi caracterizar números pares/múltiplos de 2 e números ímpares por meio das regularidades apresentadas nas respectivas sequências numéricas. Inicialmente, com a opção "Mostrar múltiplos", os alunos são orientados a clicar no número 2 para reconhecerem os números em destaque como números pares. Na sequência, os alunos precisam preencher uma tabela com os números naturais multiplicados por 2 . De maneira análoga, trabalhando com os números ímpares representados pelos números não destacados no software, em outra tabela os alunos precisam inserir a multiplicação do número natural por 2 somado 1 .

Os resultados anotados nas tabelas são considerados os modelos isolados da Teoria dos Modelos Genéricos (HEJNÝ, 2011, 2012). Da comparação entre os algarismos da unidade nos números que aparecem na tela do software e os resultados das tabelas, os estudantes chegam à etapa do modelo genérico, onde formulam uma representação genérica para os números pares e ímpares.

As regras de divisibilidade podem ser usadas para testar a primalidade de um número. Assim sendo, as Estratégias 2 e 3 foram elaboradas no sentido de possibilitar o entendimento e a construção da argumentação matemática que justifique as regras de divisibilidade por 3 e por 5, respectivamente.

Na Estratégia 2, além do software Criba de Eratóstenes, também foi utilizada a calculadora do Windows para o aluno testar a divisibilidade do número, bem como da soma dos seus algarismos por 3. O uso da calculadora permite o foco na propriedade dos números divisíveis por 3 e não nas dificuldades com o algoritmo da divisão ou com a tabuada do 3. Na Estratégia 3 , entre os primeiros 50 números naturais, os números divisíveis por 5 são testados com os fatos fundamentais da tabuada do 5 , sem apoio da calculadora do Windows.

Com a opção "Mostrar múltiplos" do software, os múltiplos do primeiro número selecionado pelo aluno ficam em destaque com a modificação da fonte preta para a fonte azul. Na seleção de um segundo número, o aluno visualizará seus múltiplos pela modificação na cor do preenchimento das quadrículas no software. Assim, os múltiplos comuns ficam destacados duas vezes (cor do número e preenchimento da quadrícula). Isso permite que o aluno possa identificar os múltiplos comuns. Na Estratégia 5, esta funcionalidade foi utilizada para o aluno determinar o mínimo múltiplo comum. 


\subsubsection{As estratégias didático-metodológicas para o software Fracciones Equivalentes}

O desenvolvimento do conteúdo de frações compreende os conhecimentos conceitual e procedimental. O conhecimento conceitual é o que se refere ao significado das frações propriamente dito. Inclui a compreensão das propriedades, princípios e notações. Enquanto o conhecimento processual envolve a fluência com as quatro operações aritméticas (FAZIO; SIEGLER, 2011; SIEGLER et al., 2013).

Estudantes do mundo todo têm dificuldades no aprendizado de frações e, geralmente, essas decorrem da falta de entendimento conceitual (FAZIO; SIEGLER, 2011). Neste sentido, as experiências de aprendizagem que permitem a exploração e a experimentação podem apoiar o desenvolvimento da compreensão conceitual das frações (ONTARIO, 2006; SIEGLER et al., 2010; WAY, 2011; CLARKE; ROCHE; MITCHELL, 2011).

Na nomeação verbal da fração, deve-se incentivar os alunos a ler símbolos de fração de uma maneira que reflita o seu significado, por exemplo, ler $3 / 5$ como "três quintos" em vez de "três sobre cinco" (ONTARIO, 2006). Esta perspectiva foi contemplada na comunicação verbal da Estratégia 6.

A interpretação de fração como parte de um todo é a mais comum e, geralmente, a mais utilizada para iniciar o ensino desse conteúdo (CLARKE; ROCHE; MITCHELL, 2011). A utilização da fração com o significado de parte/todo depende da capacidade de particionar uma quantidade contínua ou discreta em partes iguais (CLARKE; ROCHE; MITCHELL, 2011) e isto nem sempre é tarefa fácil. A dificuldade aumenta quando o denominador é um número ímpar. Neste caso, não é possível começar com a redução por metade, como em quartos ou oitavos (WAY, 2011).

No software Fracciones Equivalentes para a abordagem conceitual de frações, o inteiro já vem particionado. Além disso, as representações geométricas e simbólicas estão conectadas. A Estratégia 6 considera essas características do software de forma que o aluno possa visualizar a quantidade de partes associando-a ao denominador e possa identificar o numerador por meio da contagem da quantidade de partes coloridas nas representações.

No caso de quantidades contínuas, é comum representar o todo por figuras geométricas. Way (2011) considera importante evitar apresentar representações estereotipadas de frações aos alunos. Neste sentido, o software Fracciones Equivalentes alterna de forma aleatória entre círculo, quadrado e retângulo como as formas geométricas que representam o todo.

Nas atividades que envolvem divisão do inteiro, discreto ou contínuo, em partes iguais, é possível a compreensão dos alunos sobre a ordenação e a equivalência de frações (SIEGLER et al., 2010). Na Estratégia 7, para reconhecer frações equivalentes, os alunos utilizam um botão no software que altera, dinamicamente, as divisões de um inteiro para a obtenção de frações que sejam equivalentes à fração inicial, com a observação de novos numeradores e denominadores.

Um dos princípios na utilização de recursos digitais é o feedback sobre ações corretas e incorretas, permitindo que o estudante realize a autocorreção (WAY, 2011). Neste sentido, o 
software disponibiliza um botão que, quando acionado, verifica a equivalência da fração inicial e da fração obtida pelo aluno ao alterar a quantidade de partes.

A necessidade do incentivo da escrita e da oralidade a partir da causa e efeito (WAY, 2011), foi contemplada nas estratégias para o software Fracciones Equivalentes. Na Estratégia 6, os alunos registram o numerador e o denominador das modificações nas representações geométricas e numéricas; e na Estratégia 7, o aluno escreve os novos denominador e numerador da fração, obtida após a alteração na quantidade de partes da figura.

\subsubsection{As estratégias didático-metodológicas para o software GeoGebra}

O software GeoGebra, considerado de Geometria Dinâmica, foi adotado para a elaboração das estratégias didático-metodológicas relacionadas ao cálculo da área de superfícies limitadas por figuras planas e ao sistema de coordenadas cartesianas. Nos softwares de geometria dinâmica, as figuras geométricas são construídas e manipuladas sem que suas propriedades sejam alteradas.

O conceito de área é mais abstrato do que outras medidas (MURPHY, 2011) e não é fácil de ser compreendido (MURPHY, 2011, WINARTI et al., 2012). Neste sentido, a abordagem didática que modela a contagem de quadradinhos em malhas quadriculadas tem demonstrado melhores resultados (MURPHY, 2011). Para o conteúdo de área de figuras planas, os professores de matemática escolheram o GeoGebra.

Quanto ao uso do software em atividades do ensino fundamental, a sugestão é o fechamento da janela de Álgebra e a utilização da malha quadriculada na tela do computador (FURNER, MARINAS, 2012), como foi adotado nas cinco estratégias para o GeoGebra (de 8 a 12). Durante a elaboração das atividades, optou-se também pelo ocultamento dos eixos das coordenadas favorecendo uma visualização mais clean.

Com o uso da malha quadriculada e considerando algumas etapas da Teoria dos Modelos Genéricos (HEJNÝ, 2011, 2012), o aluno inicia a atividade fazendo a contagem da quantidade de quadradinhos que preenche a figura geométrica. Em um segundo momento, o aluno é orientado a observar as regularidades nesses modelos isolados. Dessa forma, é possível que o aluno faça uma generalização que permite a escrita da fórmula para o cálculo da área da superfície limitada pelo polígono em questão.

Em todas as estratégias que trabalham o conceito de área, os vértices dos polígonos são sobrepostos aos vértices da malha quadriculada do software. Assim, a contagem da quantidade de quadradinhos será sempre um número inteiro, fazendo com que o aluno mantenha o foco na generalização da fórmula para o cálculo da área da figura. Além disso, as linhas da malha quadriculada orientam sobre o paralelismo de dois pares de lados nos paralelogramos e de um par de lados no trapézio.

A compreensão do aluno sobre o conceito de perímetro e de área é maior quando se utiliza as formas retangulares e quadradas (WINARTI et al., 2012). Assim, a Estratégia 8 consiste em deduzir expressões para o cálculo da área de superfícies limitadas por retângulos e quadrados. Inicialmente, o cálculo da área dessas superfícies é feito pela contagem dos quadradinhos na 
malha quadriculada. Depois, os alunos utilizam as funcionalidades do GeoGebra para construir vários modelos isolados da mesma figura. São orientados a observar que a multiplicação pode ser usada como uma maneira mais eficiente de encontrar o número de quadradinhos que preenchem a figura, em vez de contar um a um. Por fim, os alunos fazem a generalização, por associação com a multiplicação, e registram a fórmula que permite calcular a área do retângulo e do quadrado.

Nas Estratégias 9, 11 e 12, o estudante utiliza as funcionalidades de construção do GeoGebra para transformar o paralelogramo, o trapézio e o losango em formas retangulares equivalentes. Enquanto que, nas Estratégias 10 e 11, as funcionalidades são utilizadas para construir um paralelogramo a partir de dois triângulos ou de dois trapézios congruentes. Como o estudante já consegue calcular a área de superfícies limitadas por paralelogramos, ele obtém a área do triângulo ou do trapézio a partir da metade da área do paralelogramo. Na Estratégia 12, o estudante constrói um losango e o inscreve em um retângulo cujas medidas da base e da altura são, respectivamente, iguais às medidas da diagonal maior e da diagonal menor do losango. Com isso, a área do losango é obtida a partir da metade da área do paralelogramo.

Nas Estratégias 10, 11 e 12, o estudante é orientado a utilizar as funcionalidades relacionadas com a geometria dinâmica para buscar a generalidade das fórmulas. $O$ aluno manipula, convenientemente, os vértices das figuras e observa que não há alteração em suas propriedades. Na Estratégia 10, mesmo com a movimentação dos vértices e a modificação do tipo de triângulo, os dois triângulos continuam formando paralelogramos e continuam congruentes; na Estratégia 11, o movimento dos vértices permite que o aluno visualize a construção dos trapézios isósceles, retângulo e escaleno; e na Estratégia 12, o movimento é em relação ao tamanho das diagonais do losango.

Quanto ao sistema de coordenadas cartesianas, pode-se afirmar que é uma ferramenta utilizada em várias áreas de conhecimento e está entre as formas mais importantes de representação em matemática (BAUTISTA et al., 2015).

As atividades são iniciadas com a configuração do software. Conforme sugerido por Furner e Marinas (2012), a janela de Álgebra é fechada e a malha quadriculada é exibida, pois auxilia na compreensão da localização do ponto no plano por meio de suas coordenadas.

A ideia de coordenadas pode ser construída a partir da ampliação dos conjuntos numéricos e de suas representações na reta numérica (BRASIL, 2016). Assim, na Estratégia 13, o estudante utiliza a opção "Exibir/Esconder Objeto" e esconde o eixo vertical. Fica apenas o eixo horizontal, representação dos números reais na reta numérica já conhecida por ele. Comandos são dados para que pontos sejam localizados no plano tendo como referência apenas um eixo. Com o procedimento, os estudantes observam os pontos na tela do seu computador e comparam com os resultados exibidos nas telas dos colegas. Como as representações diferem, os alunos percebem que considerando apenas o eixo horizontal, por exemplo, os comandos acima e abaixo não são suficientes para localizar os pontos no plano de maneira única. Os alunos são desafiados a modificar o comando para que as respostas obtidas sejam iguais. Como a conclusão é dizer a quantidade de unidades à esquerda ou à direita, e também acima 
ou abaixo, faz surgir a necessidade de trabalhar com os dois eixos coordenados (horizontal e vertical), simultaneamente. Resultado análogo é obtido quando o estudante utiliza a opção "Exibir/Esconder Objeto" e esconde o eixo horizontal.

Ainda na Estratégia 13, o estudante cria/plota um ponto e configura o software para exibir o rótulo com nome e valor do ponto. $O$ valor exibido corresponde às coordenadas do ponto. $A$ opção "Mover" auxilia no deslocamento do ponto pelo plano fazendo com que o aluno observe a alteração nos valores das coordenadas. O procedimento permite que o aluno faça a associação entre os pontos do plano e os pares ordenados.

Na Estratégia 14, o estudante também utiliza a configuração para exibir as coordenadas do ponto ("Nome \& Valor") e a opção "Mover". Depois de criar/plotar um ponto, os alunos são orientados a movê-lo pelo primeiro quadrante e anotarem as coordenadas de cinco deslocamentos. Os resultados anotados representam a segunda etapa da Teoria dos Modelos Genéricos (HEJNÝ, 2011, 2012), os modelos isolados. Da observação e do registro da regularidade no sinal das coordenadas, os estudantes chegam ao modelo genérico, terceira etapa da Teoria dos Modelos Genéricos (HEJNÝ, 2011, 2012). Aqui sim, formulam uma caracterização

genérica, em termos de sinal, para as coordenadas de pontos localizados no primeiro quadrante. No mesmo princípio, o estudante move o ponto pelos quadrantes II, III e IV.

\subsubsection{As estratégias didático-metodológicas para o software MathGV}

$\mathrm{Na}$ aprendizagem matemática, os números inteiros negativos são as primeiras quantidades que não podem ser associadas com objetos físicos e as atividades formais diferem das atividades fora da escola (QUIGLEY, 2011, SCHINDLER et al., 2017). Apesar disso, as crianças, mesmo pequenas, têm noções sobre esse tipo de número, baseadas em vivências cotidianas (KILPATRICK; SWAFFORD; FINDELL, 2001).

Aproveitando-se desse conhecimento intuitivo, várias metáforas são utilizadas para ampliar o conjunto dos números naturais, bem como interpretar as operações de forma significativa para os alunos. As ideias sugeridas incluem modelos baseados em fichas coloridas, termômetros, elevadores, débitos e créditos, balões de ar quente, pontuação em jogos e deslocamentos em reta numérica.

Embora essas metáforas sejam consideradas úteis para a introdução dos números inteiros, elas apresentam inconsistências quando se trata de auxiliar os estudantes na construção de competências relacionadas à aritmética com números inteiros (KILPATRICK; SWAFFORD; FINDELL, 2001; GREGG; GREGG, 2007; QUIGLEY, 2011; YAKES, 2017), além de não permitir a expansão destas ideias na modelagem de operações com números racionais (YAKES, 2017).

Apesar das inconsistências, existe consenso de que a utilização de metáforas na construção de procedimentos de cálculo com os números negativos auxilia na representação do raciocínio em vez de exigir que os alunos memorizem regras mecanicamente (GREGG; GREGG, 2007; BOFFERDING; WESSMAN-ENZINGER, 2017). Não existe unanimidade em relação ao melhor 
método (BOFFERDING; WESSMAN-ENZINGER, 2017). Neste sentido, recomenda-se a utilização de mais de um modelo (AUBRY, 2009; GHAZALI; AYUB; OTHMAN, 2013; BELLAMY, 2015).

$\mathrm{Na}$ elaboração das estratégias didático-metodológicas relacionadas ao conteúdo de números inteiros e propriedades, os professores de matemática optaram pela metáfora do deslocamento sobre a reta numérica. A expectativa dos professores era utilizar recursos digitais para auxiliar os alunos nas dificuldades relacionadas às operações com esses números.

A escolha da metáfora da reta numérica se deu em função da possibilidade de (a) ampliar a interpretação das operações com números inteiros para as operações com números racionais; (b) relacionar operações de adição e subtração; (c) compreender valor absoluto de um número inteiro como a sua distância em relação ao zero; (d) interpretar a multiplicação como escala (YAKES, 2017); e (e) utilizar o software MathGV para construir um objeto virtual que pudesse ser manipulado pelos alunos.

Existem vários tipos de retas numéricas que são utilizadas como ferramentas didáticas (TEPPO; van den HEUVEL-PANHUIZEN, 2014). Dentre os modelos de reta mais usados estão as estruturadas (DIEZMANN; LOWRIE; SUGARS, 2010) que são caracterizadas por pontos equidistantes ou marcações, que representam todos os números. Sendo que os positivos se situam à direita do zero e os negativos à esquerda. Particularmente, os números inteiros são representados sobre as marcações destacadas na linha numérica ou com indicações de vetores.

Um vetor corresponde a um segmento de reta, geralmente representado por uma seta (TEPPO; van den HEUVEL-PANHUIZEN, 2014; YAKES, 2017). O comprimento do segmento é o valor absoluto do número representado, enquanto que a seta indica o sinal do número. Além da utilização da seta, são usadas cores diferentes para números positivos e negativos (YAKES, 2017).

Nas estratégias didático-metodológicas para números inteiros com o software MathGV, convencionou-se que os números positivos serão representados em tons de azul e os negativos em tons de verde. Optou-se também pela reta estruturada e pela representação do número inteiro por segmento não orientado que, por comodidade na configuração do software, não se fez a representação com setas. Em vez disso, o sinal positivo foi interpretado como deslocamento para a direita e o sinal negativo como deslocamento para a esquerda. 0 software permite que se faça a configuração das retas estruturadas tanto na horizontal quanto na vertical e também de cores, para representar os deslocamentos por segmentos de reta.

Uma vez que as teorias de cognição numérica propõem que o conhecimento de números inteiros seja organizado de forma que os símbolos de números estejam conectados a representações não verbais de quantidade em uma matriz ordenada e orientada horizontalmente (SIEGLER; THOMPSON; SCHNEIDER, 2011), optou-se pela configuração da reta numérica na horizontal em todas as estratégias.

A interatividade no uso da tecnologia permite que o estudante manipule representações visuais dinâmicas do objeto virtual como faria em uma manipulação concreta (RUBIN et al., 2014). Desta forma, outra vantagem do software MathGV para números inteiros é a possibilidade de o aluno manipular a reta numérica ampliando a quantidade de números que 
pode ser representada, bem como a escala (Zoom) e a parte visível da reta. Além disso, é possível que o estudante delete uma operação e aproveite a reta numérica para representar outra operação, sem a necessidade de configurar um novo objeto virtual.

A realização das atividades no MathGV se inicia com a configuração da reta numérica estruturada na horizontal. Configurado o objeto virtual, o estudante utiliza as funcionalidades do software para representar as operações. O deslocamento correspondente à primeira parcela tem ponto de partida no zero e ponto final indicado pela quantidade de unidades que representa o número. Na segunda parcela, o deslocamento inicia-se no ponto final do deslocamento indicado na primeira parcela e ponto final indicado pela quantidade de unidades que representa o número.

Ao considerar a Teoria dos Modelos Genéricos (HEJNÝ, 2011, 2012) nas estratégias, o aluno manipula o objeto virtual e representa um conjunto de operações. Na sequência, sua atenção é solicitada para que observe padrões e regularidades considerando o sinal das parcelas, a representação na reta numérica e também o resultado. O estudante abstrai das regularidades e características que permitem a escrita da generalização dos procedimentos para resolver as operações, sem a utilização do software.

Na sequência, o estudante efetua um conjunto de operações utilizando o procedimento que ele descreveu e registrou. Caso o estudante tenha dúvidas, ele poderá verificar o cálculo manipulando o objeto virtual construído por meio do software.

Nas Estratégias 15 e 16, para formalizar o procedimento de cálculo, faz-se uma generalização do procedimento em termos do módulo e do sinal das parcelas. Em seguida, propõem-se outras operações com duas parcelas e sugere-se que o aluno confira os cálculos utilizando o software. Para finalizar a Estratégia 15, propõem-se operações com três parcelas, no sentido da espiral ascendente, ampliando o procedimento.

Na representação da reta numérica, pode-se indicar que o sinal de menos está associado ao oposto de um número (YAKES, 2017), como por exemplo $-(+5)=-5$ e $-(-5)=+5$. Essa ideia foi utilizada na a Estratégia 16 para efetuar operações como $(+2)-(+5)$. Para finalizar, propõem-se operações com três parcelas, envolvendo o sinal de adição e o sinal de menos com sentido simétrico. Para concluir a atividade, sugere-se que o aluno confira os cálculos utilizando o software.

Na Estratégia 17, para reconhecer o zero "0" como elemento neutro da adição algébrica, convencionou-se que parcela de valor zero " 0 " indica que não há deslocamento, dentro da metáfora da reta numérica. O aluno conclui a atividade, sem utilizar o software, com um procedimento para efetuar a adição de números inteiros onde as parcelas são números simétricos. Enquanto que, na Estratégia 18, o estudante é orientado a seguir a ordem de prioridade entre colchetes e parênteses.

\subsubsection{A estratégia didático-metodológica para o software Poly}

Muitos objetos do mundo físico são composições aproximadas das formas geométricas tridimensionais (NCTM, 2010). O estudo das formas geométricas básicas ajuda o aluno a 
desenvolver um tipo especial de pensamento que lhe permite organizar e descrever o tamanho dos objetos do mundo ao seu redor.

No ensino fundamental, com o estudo dos sólidos geométricos, espera-se que os alunos indiquem características das formas geométricas tridimensionais e bidimensionais e associem figuras espaciais às suas planificações e vice-versa (BRASIL, 2016).

Na Estratégia 19, para o software Poly, foi considerado o desenvolvimento dessas habilidades. A barra de rolagem permite que o aluno transite da forma geométrica tridimensional para a bidimensional e vice-versa. O software pode ser configurado para dar visibilidade aos elementos das formas geométricas. A associação dessas duas funcionalidades permite o desenvolvimento da linguagem e dos conceitos relacionados às figuras tanto no formato 3D quanto 2D.

É possível configurar o software para dar visibilidade às faces da figura. $O$ aluno planifica a figura 3D e reconhece, na figura plana, os diferentes polígonos que formam a figura espacial. Pode-se também configurá-lo para dar visibilidade às arestas e aos vértices da figura. Analogamente, o aluno planifica a figura e associa as arestas com o encontro de duas faces, ou seja, com a interseção dos polígonos na figura planificada. E pela transição do formato 3D para o 2D, o aluno reconhece o vértice da figura 3D como a interseção de três arestas.

\subsection{Validação das estratégias didático-metodológicas na prática docente de matemática}

Foi possível aplicar e validar 11 das 19 estratégias didático-metodológicas desenvolvidas para os software educativos gratuitos de matemática, contemplando as Turmas A e B necessárias para a análise (Tabela 2). Algumas estratégias não foram validadas e outras se mostraram insuficientes para análise. Dentre as dificuldades encontradas estavam (a) indisponibilidade do laboratório de informática, (b) instabilidade da internet, (c) falta de sincronismo do conteúdo matemático com o cronograma de aulas do professor, (d) não convencimento dos professores para uso de outros recursos na prática docente e (e) greve no sistema público de ensino que comprometeu o calendário de aulas dos professores.

Tabela 2 - Número de questões e de alunos nas situações avaliativas das atividades estratégico-metodológicas validadas pelos professores de matemática

\begin{tabular}{|c|c|c|c|c|}
\hline \multirow{2}{*}{ Software } & \multirow{2}{*}{$\begin{array}{c}\text { Estratégia } \\
\text { no }^{\circ}\end{array}$} & \multirow{2}{*}{$\begin{array}{l}\text { No Questões } \\
\text { nos Exercícios }\end{array}$} & \multicolumn{2}{|c|}{$\begin{array}{c}\text { No Alunos por } \\
\text { Situação Avaliativa }\end{array}$} \\
\hline & & & L e LS & $S$ e $S L$ \\
\hline \multirow{4}{*}{ Criba de Eratóstenes } & 1 & 4 & 76 & 24 \\
\hline & 2 & 5 & 39 & 45 \\
\hline & 3 & 6 & 20 & 65 \\
\hline & 4 & 8 & 43 & 23 \\
\hline
\end{tabular}




\begin{tabular}{|c|c|c|c|c|}
\hline & 5 & 9 & 22 & 101 \\
\hline \multirow{2}{*}{ GeoGebra } & 13 & 11 & 16 & 22 \\
\cline { 2 - 5 } & 15 & 8 & 55 & 62 \\
\cline { 2 - 5 } & 16 & 7 & 25 & 18 \\
\cline { 2 - 5 } & 17 & 14 & 50 & 19 \\
\hline \multirow{2}{*}{ MathGV } & 18 & 14 & 47 & 98 \\
\hline
\end{tabular}

L: laboratório de informática, LS: laboratório e depois sala de aula, S: sala de aula, SL: sala de aula e depois laboratório

Fonte: Os autores.

As aulas no laboratório de informática foram conduzidas sem problemas pelos professores de matemática. A organização estrutural das estratégias realmente auxiliou os professores e orientou os alunos durante as aulas. Quanto ao desempenho dos alunos, o relato de um professor afirmou que turmas de alunos que utilizaram os software tiveram melhor desempenho que turmas de alunos que não foram levadas ao laboratório de informática. Foi observado também

que alunos dispersos em sala de aula ficaram interessados em concluir a atividade com o software, o que geralmente não acontece em sala de aula.

O resultado do teste Kruskal-Wallis indica que não há diferença significativa entre 0 percentual de acertos das situações avaliativas da Estratégia 1, 2 e 5 para o software Criba de Eratóstenes e o conceito de números primos e de divisibilidade (Tabela 3); das Estratégias 15 e 18 para o software MathGV e a aritmética dos números inteiros e propriedades; e da Estratégia 19 para o estudo dos sólidos geométricos com o software Poly (Tabela 4).

Tabela 3 - Medianas do percentual de acertos nas situações avaliativas das Estratégias 1, 2, 3, 4 e 5 para o software Criba de Eratóstenes e da Estratégia 13 para o GeoGebra

\begin{tabular}{|c|c|c|c|c|c|c|c|}
\hline \multirow{2}{*}{ Turma } & \multirow{2}{*}{ Situação Avaliativa } & \multicolumn{6}{|c|}{ Estratégia no } \\
\hline & & 1 & 2 & 3 & 4 & 5 & 13 \\
\hline$A$ & L - Laboratório & $100,00 a$ & $62,00 a$ & $82,08 a b$ & $59,37 b$ & $94,44 a$ & $90,90 a$ \\
\hline$A$ & LS - Laboratório e Sala & $100,00 a$ & $67,00 a$ & $91,67 a$ & $83,12 a$ & $100,00 a$ & $63,63 b$ \\
\hline B & S - Sala & $75,00 a$ & $57,00 a$ & $77,50 b$ & $70,62 a b$ & $88,89 a$ & $100,00 a$ \\
\hline \multirow[t]{2}{*}{ B } & SL - Sala e Laboratório & $100,00 a$ & $60,00 a$ & $85,41 a b$ & $87,49 a$ & $98,89 a$ & $95,45 a$ \\
\hline & p-valor & 0,5219 & 0,4052 & 0,0109 & 0,0076 & 0,0672 & 0,0012 \\
\hline
\end{tabular}


Medianas seguidas por letras diferentes nas colunas se diferem entre si pelo teste de Kruskal-Wallis ao nível de 0,05 de significância.

Fonte: Os autores.

Tabela 4 - Medianas do percentual de acertos nas situações avaliativas das Estratégias 15, 16, 17 e 18 para o software MathGV e da Estratégia 19 para o Poly

\begin{tabular}{|c|c|c|c|c|c|c|}
\hline \multirow{2}{*}{ Turma } & \multirow{2}{*}{ Situação Avaliativa } & \multicolumn{5}{|c|}{ Estratégia no } \\
\hline & & 15 & 16 & 17 & 18 & 19 \\
\hline$A$ & L - Laboratório & $100,00 a$ & $82,14 b$ & $78,57 b$ & $81,43 a$ & $55,00 a$ \\
\hline$A$ & LS - Laboratório e Sala & $100,00 a$ & $92,86 b$ & $85,71 a$ & $75,00 a$ & $50,00 a$ \\
\hline B & S - Sala & $100,00 a$ & $68,92 b$ & $85,71 a$ & $82,86 a$ & $50,00 a$ \\
\hline \multirow[t]{2}{*}{ B } & SL - Sala e Laboratório & $100,00 a$ & $100,00 a$ & $79,28 a b$ & $85,71 a$ & $51,56 a$ \\
\hline & p-valor & 0,8528 & 0,147 & 0,0171 & 0,1466 & 0,2543 \\
\hline
\end{tabular}

Medianas seguidas por letras diferentes nas colunas se diferem entre si pelo teste de Kruskal-Wallis ao nível de 0,05 de significância.

Fonte: Os autores.

Para as Estratégias 3 e 4, com o software Criba de Eratóstenes, não houve diferença significativa nas situações avaliativas LS e SL realizadas para a sequência laboratório de informática e depois sala de aula e vice-versa. Considerando as aulas somente em um dos ambientes com as aulas em ambos os ambientes, na Estratégia 3 houve diferença significativa da Turma B somente em sala de aula - S para a Turma A sequência laboratório e sala - LS; e na Estratégia 4 da Turma A somente laboratório - L para a Turma A laboratório e sala - LS e Turma B sala e laboratório (Tabela 3).

O software Criba de Eratóstenes, como um recurso didático para auxiliar nos conceitos de números primos e de divisibilidade, pode ser utilizado para a introdução do conteúdo ou para complementá-lo. Em ambos os casos, o ambiente da sala de aula se faz necessário, antes ou depois do laboratório de informática.

$\mathrm{Na}$ Estratégia 13, que trabalha o sistema de coordenadas cartesianas no software GeoGebra, houve diferença significativa apenas na Turma A que iniciou o conteúdo com a 
estratégia no laboratório de informática e depois seguiu para a sala de aula - LS (Tabela 3). 0 software GeoGebra se mostrou um recurso eficaz quando utilizado após a aula em sala ou sozinho. Não há necessidade do professor usar o software e depois complementar o conteúdo em sala de aula.

A leitura de guias, plantas e mapas contribui para desenvolver as ideias iniciais sobre a localização no plano (BRASIL, 1998). Entretanto, essas ideias precisam ser transpostas para o sistema de coordenadas cartesianas. A transposição não se dá de forma fácil, já que exige a construção de dois eixos orientados perpendiculares e demarcados com números reais em intervalos congruentes. A utilização de software pode facilitar essa representação. Depois de representar pontos no plano com o software, fazer a mesma representação no papel em sala de aula pode desmotivar o aluno. Esse pode ser um dos motivos para a situação avaliativa LS ter sido menos satisfatória, pois a Turma A iniciou o conteúdo no laboratório de informática e depois seguiu para a sala de aula (Tabela 3 ).

Na Estratégia 16 para o software MathGV, o percentual de acertos foi maior na situação avaliativa LS com aula em sala e laboratório, nessa ordem. As demais situações LS, L e S não apresentaram diferença significativa nos acertos. Para a Estratégia 17, do mesmo software, não houve diferença entre a situação LS, com aula no laboratório e depois na sala, e a situação S, com aula somente em sala. No entanto, as situações avaliativas LS e $\mathrm{S}$ diferem significativamente da situação $L$, com aula apenas no laboratório de informática. O resultado da Turma B com aula em sala e no laboratório de informática - SL não se difere das demais situações LS, L e S (Tabela 4). Para a abordagem do conteúdo que envolve números inteiros e suas propriedades, observa-se que a sequência de aulas em sala e depois laboratório de informática com o software MathGV pode favorecer a prática docente de matemática.

As atividades em sala de aula se caracterizam pela participação do aluno em termos de oralidade, sem prescindir da escrita. Enquanto que nas atividades desenvolvidas nos laboratórios de informática a atenção do aluno é focada nas suas ações sobre o software, na observação da tela do computador e na reflexão em torno da causa e do efeito. Para os anos iniciais do ensino

fundamental, Nacarato (2012) salienta que a oralidade é imprescindível para a elaboração conceitual em matemática. Portanto, os contextos de sala de aula e laboratório se complementam para que oralidade e escrita se articulem e se beneficiem para gerar conceitos matemáticos.

A utilização de software não tem impacto positivo apenas na abordagem do conteúdo. 0 fato das novas tecnologias fazerem parte do cotidiano dos alunos faz com que as atividades com esse recurso sejam mais atrativas. A motivação (HENDRES; KAIBER, 2005; TANBELLINI; BRANDÃO, 2010), a melhoria na compreensão da realidade e na comunicação (HENDRES; KAIBER, 2005), o feedback imediato da atividade e a possibilidade do aluno avançar no conteúdo (TANBELLINI;

BRANDÃO, 2010) são aspectos dentre os efeitos do uso de computadores na aprendizagem dos alunos. 
As tradicionais aulas em sala ganham novos direcionamentos. Seja com o desenvolvimento de estratégias investigativas seguindo diferentes tendências metodológicas para a construção de um conhecimento matemático significativo (MENDES, 2009) ou seja com a adoção da informática que não significa deixar de usar outras tecnologias já conhecidas (lápis, papel, giz, quadro), apenas considera-se adequações necessárias (BORBA; PENTEADO, 2016).

\section{Conclusão}

As estratégias didático-metodológicas desenvolvidas foram estruturadas para que 0 professor tenha, durante a aula, uma sequência de orientação com foco na construção do conhecimento matemático, bem como um material para auxiliá-lo no uso dos software deixando-o mais confiante num ambiente informatizado.

A estrutura e a representação adotadas nas estratégias didático-metodológicas, com passos sequenciais e ilustrações, permitiu que os alunos estabelecessem o seu próprio ritmo de aprendizado. Com isso, o desenvolvimento das atividades de ensino se mostrou prazeroso e foi fator de motivação para o aluno conclui-la com a finalidade de atingir o objetivo proposto na atividade das aulas dos professores participantes.

$\mathrm{Na}$ maioria dos conteúdos abordados, o uso conjunto dos software e das estratégias didático-metodológicas desenvolvidas e investigadas se mostraram favoráveis para a prática docente de Matemática no Ensino Fundamental II. Principalmente, após o conteúdo ter sido ministrado em sala de aula. Portanto, com atividades investigativas ou não, a sala de aula ainda se mantém presente no ensino de Matemática.

\section{Agradecimentos}

Os autores agradecem ao apoio financeiro da Fundação de Amparo à Pesquisa do Estado de Minas Gerais (FAPEMIG) e do Conselho Nacional de Desenvolvimento Científico e Tecnológico (CNPq).

\section{Referências}

ARAúJO, J. P. A. P.; RIBEIRO JÚNIOR, J. G. R. Plataforma Matematech: um recurso didático no ensino de matemática nos anos iniciais do ensino fundamental. Informática na Educação: teoria

\& prática, Porto Alegre, v. 20, n. 2, p. 17-35, maio/ago. 2017.

AREIAS, G. B.; NOBRE, I. A. M.; PASSOS, M. L. S. Uso de tecnologias computacionais no processo de ensino e aprendizagem nas escolas públicas do município de Piúma. Revista Eletrônica Debates em Educação Científica e Tecnológica, v. 6, n. 2, p. 101-115, jun. 2016.

ARTIGUE, M. Learning mathematics in a CAS environment: the genesis of a reflection about instrumentation and the dialectics between technical and conceptual work. International Journal of Computers for Mathematical Learning, v. 7, p. 245-274, 2002.

ASSIS, C. C.; BEZERRA, M. C. A. Formação continuada de professores de Matemática: integrando softwares educativos à prática docente. In: CONFERÊNCIA INTERAMERICANA DE EDUCAÇÃO MATEMÁTICA - CIAEM, 13., 2011, Recife. Anais... Recife: Universidade Federal de Pernambuco, 2011. p. 1-12. 
AUBRY, M. Metaphors in mathematics: introduction and the case of algebraic geometry, 2009. Disponível em: <https://ssrn.com/abstract=1478871>. Acesso em: 05 jun. 2017.

BALANSKAT, A.; BLAMIRE, R.; KEFALA, S. The ICT impact report: a review of studies of ICT impact on schools in Europe. Brussels: European Schoolnet, 2006.

BASSANI, P. S.; PASSERINO, L. M.; PASQUALOTTI, P. R.; RITZEL, M. I. Em busca de uma proposta metodológica para o desenvolvimento de software educativo colaborativo. Revista Novas Tecnologias na Educacロão, v. 4, n. 1, p. 1-10, 2006.

BATISTA, S. C. F.; BARCELOS, G. T.; AFONSO, F. F. Tecnologias de informação e comunicação no estudo de temas matemáticos. In: CONGRESSO NACIONAL DE MATEMÁTICA APLICADA E COMPUTACIONAL, 28., 2005, Santo Amaro. Anais... Santo Amaro: SBMAC, 2005. Disponível em: <http://www.sbmac.org.br/eventos/cnmac/cd_xxviii_cnmac/resumos\%20estendidos/silvia_bat

ista_SE5.pdf>. Acesso em: 24 maio 2014.

BAUTISTA, A.; CAÑADAS, M. C.; BRIZUELA, B. M.; SCHLIEMANN, A. D. Examining how teachers use graphs to teach mathematics during a professional development program. Journal of Education and Training Studies, v. 3, n. 2, p.91-106, mar. 2015.

BELLAMY, A. A critical analysis of teaching and learning negative numbers. Philosophy of Mathematics Education Journal, n. 29, p. 1-12, jul. 2015. Disponível em:

<http://socialsciences.exeter.ac.uk/education/research/centres/stem/publications/pmej/>. Acesso em: 10 set. 2017.

BOFFERDING, L.; WESSMAN-ENZINGER, N. Subtraction involving negative numbers: connecting to whole number reasoning. The Mathematics Enthusiast, v. 14, n. 1, p. 241-262, 2017.

BORBA, M. C.; PENTEADO, M. G. Informática e educação matemática. 5 ed. Belo Horizonte: Autêntica, 2016.

BORGES, M. F. V. Inserção da informática no ambiente escolar: inclusão digital e laboratórios de informática numa rede municipal de ensino. In: CONGRESSO DA SOCIEDADE BRASILEIRA DE COMPUTAÇÃO, 28., 2008, Belém. Anais... Porto Alegre: SBC, 2008. p. 146-155.

BRASIL. Parâmetros curriculares nacionais: matemática. Brasília: MEC/SEF, 1998.

BRASIL. Ministério da Educação. Base Nacional Comum Curricular. Proposta preliminar. Segunda versão revista. Brasília: MEC, 2016. Disponível em:

<http://basenacionalcomum.mec.gov.br/images/BNCC_publicacao.pdf>. Acesso em: 20 abr. 2017.

BRUM, A. L.; PEREIRA, E. C. Implicações da investigação matemática no espaço educacional com a inserção das tecnologias digitais. Revista Eletrônica de Educação Matemática - REVEMAT,

Florianópolis, v. 13, n. 2, p. 132-148, 2018. DOI: http:// doi.org/105007/1981-1322.2018v13n2p132.

BURNS, P. K.; BOZEMAN, W. C. Computer-assisted instruction and mathematics achievement: is there a relationship? Educational Technology, v. 21, n. 10, p. 32-39, 1981.

CAVELlUCCI, L. C. B.; CENRY, R. Z.; BÚRIGO, C. C. D.; RAMOS, E. M. F.; SILVA, M. R.; HASSAN, E. B. Curso de especialização em educação na cultura digital: guia de implantação. Brasília: Ministério da Educação, 2013.

CEO FORUM ON EDUCATION AND TECHNOLOGY. Key building blocks for student achievement in the 21st century. Washington: CEO Forum, 2001.

CHAKRABARTY, A.; PURKAYASTHA, B. S. Na analysis of some prime generating sieves. The IUP Journal of 
Computer Sciences, v. 4, n. 1, p. 16-26, 2010.

CHINELLATO, T. G.; JAVARONI, S. L. A formação dos professores de matemática para o uso de tecnologias digitais na cidade de Limeira/SP. In: CONGRESSO NACIONAL DE FORMAÇÃO DE PROFESSORES, 2.; CONGRESSO ESTADUAL PAULISTA SOBRE FORMAÇÃO DE EDUCADORES, 12., 2014, Águas de Lindóia. Anais... São Paulo: Unesp, 2014. p. 3335-3345.

CLARKE, D.; ROCHE, A.; MITCHELL, A. One-to-one student interviews provide powerful insights and clear focus for the teaching of fractions in the middle years. In: WAY, J.; BOBIS, J. Fractions: teaching for understanding. Australia: Australian Association of Mathematics Teachers, 2011. p. 23-41.

COLEY, R. J.; CRADLER, J.; ENGEL, P. K. Computers and classrooms: the status of technology in U.S. schools. Princeton: Policy Information Center/Educational Testing Service, 1997.

COX, M. J. The effects of information technology on students' motivation: summary report. London: National Council for Educational Technology/King's College London, 1997.

CURTIS, M.; TULARAM, G. A. The importance of numbers and the need to study primes: the prime questions. Journal of Mathematics and Statistics, v. 7, n. 4, p. 262-269, 2011.

DIEZMANN, C. M.; LOWRIE, T.; SUGARS, L. A. Primary students' success on the structured number line. Australian Primary Mathematics Classroom, v. 15, n. 4, p. 24-28, 2010.

FAZIO, L.; SIEGLER, R. Educational practices series: teaching fractions. Athens: International Bureau of Education, 2011.

FIGUEIRA-SAMPAIO, A. S.; SANTOS, E. E. F. CARRIJO, G. A. A constructivist computational tool to assist in learning primary school mathematical equations. Computers and Education, v. 53, n. 2, p. 484-492, 2009.

FIGUEIRA-SAMPAIO, A. S.; SANTOS, E. E. F.; CARRIJO, G. A. Mapping free software used to teach measurement and proportion. In: CONGRESO INTERNACIONAL INFORMÁTICA EDUCATIVA - TISE, 10., 2014, Fortaleza. Anais... Chile: Universidad de Chile, 2014. p. 452-456.

FIGUEIRA-SAMPAIO, A. S.; SANTOS, E. E. F.; CARRIJO, G. A.; CARDOSO, A. Survey of teaching practices with educational software for mathematics in Brazil. AWERProcedia Information Technology \& Computer Science, v. 2, p. 358-363, nov. 2012.

FIGUEIRA-SAMPAIO, A. S.; SANTOS, E. E. F.; CARRIJO, G. A.; CARDOSO, A. Survey of mathematics practices with concrete materials used in Brazilian schools. Procedia - Social and Behavioral Sciences, v. 93 , p. $151-157$, oct. 2013

FURNER, J. M.; MARINAS, C. A. Connecting geometry, measurement, and algebra using Geogebra for the elementary grades. In: INTERNATIONAL CONFERENCE ON TECHNOLOGY IN COLLEGIATE MATHEMATICS ICTCM), 4. 2012, Orlando. Proceedings... Orlando: Pearson Education, 2012. p. 63-72.

GARDETE, C.; CESAR, M. Equac口ão (im)possivivel: um caminho para a sua solução. In: SEMINARIO DE INVESTIGACIÁO EM EDUCACᄆÃO MATEMATICA, 17., 2006, Setúbal. Actas... Setúbal: APM, 2006. 1 CDROM.

GHAZALI, M.; AYUB, A.; OTHMAN, A. R. Preschool children's representation of numbers on a linear number line: implications to teaching and learning of number concepts. Journal of Humanities and Social Science, $v$. 14, n. 6, p. 87-92, set./oct. 2013.

GLADCHEFF, A. P.; OLIVEIRA, V. B.; SILVA, D. M. O software educacional e a psicopedagogia no ensino de matemática direcionado ao ensino fundamental. Revista Brasileira de Informática na Educac口ão, v. 8, p. 63-70, 2001. 
GOULART, D. A. O.; SILVA, R. C. Introduzindo o conceito de ângulo no ensino fundamental com auxílio do Geogebra. In: ENCONTRO MINEIRO DE EDUCAÇÃO MATEMÁTICA - EMEM, 7., 2015, São João Del-Rei. Anais... São João Del-Rei: SBEM-MG, 2015. p. 1-19.

GREGG, J.; GREGG, D. U. A context for integer computation. Mathematics Teaching in the Middle School, v. 13, n.1, p. 46-50, aug. 2007.

GROS, B. The dialogue between emerging pedagogies and emerging technologies. In: GROS, E.; KINSHUK; MAINA, M. (Ed.). The future of ubiquitous learning: learning designs for emerging pedagogies. Berlin: Springer, 2016. p. 3-23.

HENDRES, C. A.; KAIBER, C. T. A utilização da informática como recurso didático nas aulas de matemática. Acta Scientiae, v. 7, n. 1, p. 25-38, jan./jun. 2005.

HEJNÝ, M. The process of discovery in teaching focusing on building schemes. In: INTERNATIONAL SYMPOSIUM ELEMENTARY MATHEMATICS TEACHING - SEMT '11, 2011, Prague. Proceedings... Prague: Charles University, 2011. p. 150-157.

HEJNÝ, M. Exploring the cognitive dimension of teaching mathematics through scheme-oriented approach

to education. Orbis Scholae, v. 6, n. 2, p. 41-55, 2012. Disponível:

<http://www.orbisscholae.cz/archiv/2012/2012_2_03.pdf>. Acesso em: 05 mar. 2013.

KILPATRICK, J.; SWAFFORD, J.; FINDELL, B. Developing proficiency with other numbers. In: KILPATRICK, J.; SWAFFORD, J.; FINDELL, B. (Ed.). Adding it up: helping children learn mathematics. Washington: National Academy Press, 2001. p. 231-254.

KULIK, J. A. School mathematics and science programs benefit from instructional technology. InfoBrief Science Resource Statistics, p. 1-5, 2002. Disponível em: <https://files.eric.ed.gov/fulltext/ED472100.pdf>. Acesso em: 17 maio 2016.

KULIK, C. C.; KULIK, J. A. Effectiveness of computer-based education in colleges. In: ANNUAL MEETING OF THE AMERICAM EDUCATIONAL RESEARCH ASSOCIATION, 69., 1985, Chicago. Proceedings... Chicago: American Educational Research Association, 1985. p. 1-50.

KURZ, T. L.; GARCIA, J. The complexities of teaching prime decomposition and multiplicative structure with tools to preservice elementary teachers. Journal of Research in Education, v. 22, n. 2, p. 169-192, 2012.

LOPES, M. M. Contribuições do software Geogebra no ensino e aprendizagem de trigonometria. In: CONFERÊNCIA INTERAMERICANA DE EDUCAÇÃO MATEMÁTICA - CIAEM, 13., 2011, Recife. Anais... Recife: UFP, 2011. p. 1-12.

LOPES, M. M. Sequência didática para o ensino de trigonometria usando o software GeoGebra. Bolema, v. 27, n. 46, p. 631-644, ago. 2013.

LOVIS, K. A.; FRANCO, V. S. Reflexões sobre o uso do GeoGebra e o ensino de geometria euclidiana. Informática na Educação: teoria \& prática, Porto Alegre, v. 16, n. 1, p. 149-160,

jan./jul. 2013

MARCHESE, T. J. The new conversations about learning: insights from neuroscience and anthropology, cognitive science and work place studies. In: AAHE CONFERENCE ON ASSESSMENT \& QUALITY (Ed.). Assessing impact: evidence and action. Washington: American Association for Higher Education, 1997. p. 79-95.

MENDES, I. A. Matemática e investigação em sala de aula: tecendo redes cognitivas na aprendizagem. São Paulo: Livraria da Física, 2009.

MURPHY, C. The role of subject knowledge in primary prospective teachers' approaches to teaching the 
topic of area. Journal of Mathematics Teacher Education, v. 15, n. 3, p. 187-206, june 2012.

NACARATO, A. M. A comunicação oral nas aulas de Matemática nos anos iniciais do ensino fundamental. Revista Eletrônica de Educação, v. 6, n. 1, p. 9-26, maio 2012.

NATIONAL CENTRE FOR TECHNOLOGY IN EDUCATION. Educational software, 2008. Disponível em: <http://www.ncte.ie/documents/advicesheets/21SoftwareEducationalNov08.pdf>. Acesso em: 26 nov. 2009.

NATIONAL COUNCIL OF TEACHERS OF MATHEMATICS - NCTM. Principles and standards for school mathematics. Reston, VA: NCTM, 2000.

Two- and three- dimensional shapes, and area and volume. Reston, VA: NCTM, 2010.

OLIVEIRA, C. C.; COSTA, J. W.; MOREIRA, M. Ambientes informatizados de aprendizagem:

produc口ão e avaliac口ão de software educativo. São Paulo: Papirus, 2001.

OLIVEIRA, G. P.; GONÇALVES, M. D. Construções em Geometria Euclidiana Plana: as perspectivas abertas por estratégias didáticas com tecnologias. Bolema, v. 32, n. 60, p. 92-116, abr. 2018.

ONTARIO. Ministry of Education. Number sense and numeration, grades 4 to 6: fractions. Ontario: Queen's Printer for Ontario, 2006.

PONTE, J. P.; GUERREIRA, A.; CUNHA, H. DUARTE, J.; MARTINHO, H.; MARTINS, C.; MENEZES, L.; MENINO, H.; PINTO, H.; SANTOS, L.; VARANDAS, J. M.; VEIA, L.; VISEU, F. A comunicação nas práticas de jovens professores de matemática. Revista Portuguesa de Educação, Braga, v. 2, n. 20, p. 39-74, 2007.

QUIGLEY, M. The centrality of metaphor in the teaching of mathematics. Veredas - Revista de Estudos Linguísticos, v. 15, n. 2, p. 57-69, 2011.

R DEVELOPMENT CORE TEAM. $R$ : a language and environment for statistical computing. Vienna, Áustria: The R Foundation for Statistical Computing, 2011. Disponível em: <http://www.R-project.org>. Acesso em: 15 jun. 2015.

RAMOS, J. L., TEOdORO, V. D., MAIO, V. M., CARVALHO, J. M.; FERREIRA, F. M. Sistema de Avaliac口ão, Certificac口ão e Apoio à Utilizac口ão de Software para a Educac口ão e Formac口ão. Cadernos SACAUSEF I. Lisboa: DGIDDC/ME, 2005.

RIBAS, E.; VIALI, L.; LAHM, R. Educação com tecnologias digitais: questões didáticas que contribuem para aprendizagem. In: SIMPÓSIO INTERNACIONAL DE EDUCAÇÃO A DISTÂNCIA, ENCONTRO DE PESQUISADORES EM EDUCAÇÃO A DISTÂNCIA - SIED:EnPED, 2016, São Carlos. Anais... São Carlos: UFSCar. p. 1-13.

RUBIN, T. J.; MARCELINO, J.; MORTEL, R.; LAPINID, M. R. C. Activity-based teaching of integer concepts and its operations. In: DLSU RESEARCH CONGRESS, 2014, Manila. Proceedings... Manila: De La Salle University, 2014. p. 1-16.

RUMSEY, C.; LANGRALL, C. W. Promoting mathematical argumentation: these evidence-based instructional strategies can lead to deeper mathematical conversations in upper elementary school classrooms. Teaching Children Mathematics, v. 22, n. 7, p. 413-419, mar. 2016.

SANTOS, E. E. F.; FIGUEIRA-SAMPAIO, A. S.; CARRIJO, G. A. Mapping free educational software used to develop geometric reasoning. Procedia - Social and Behavioral Sciences, v. 182, p. 136-142, may 2015.

SANTOS, E. E. F.; FIGUEIRA-SAMPAIO, A. S.; CARRIJO, G. A. Mapping free educational software intended for the development of numerical and algebraic reasoning. International Journal of Learning, Teaching and 
Educational Research, v. 16, n. 11, p. 45-66, nov. 2017.

SCHINDLER, M; HUBMANN, S.; NILSSON, P.; BAKKER, A. Sixth-grade students' reasoning on the order relation of integers as influenced by prior experience: an inferentialist analysis. Mathematics Education Research Journal, v. 29, n. 4, p. 471-492, dec. 2017.

SIEGLER, R. S.; THOMPSON, C. A.; SCHNEIDER, M. An integrated theory of whole number and fractions development. Cognitive Psychology, v. 62, n. 4, p. 273-296, june 2011.

SIEGLER, R.S.; FENNELL, F.; CARPENTER, T.; WAY, J. Developing effective fractions instruction for kindergarten through 8th grade. IES Practice Guide. Washington: IES, 2010.

SIEGLER, R. S.; FAZIO, L. K.; BAILEY, D. H.; ZHOU, X. Fractions: the new frontier for theories of numerical development. Trends in Cognitive Sciences, Cambridge, v. 17, n. 1, p. 13-19, jan. 2013

SIVIN-KACHALA, J.; BIALO, E. R. Research report on the effectiveness of technology in schools. Washington: Software and Information Industry Association, 2000.

TANBELLINI, M. J. G. S.; BRANDÃO, L. O. O uso da geometria interativa como facilitador no ensino e aprendizagem de matemática: estudo com duas turmas de sexta série do ensino fundamental. In: WORKSHOP SOBRE INFORMÁTICA NA ESCOLA, 16., Belo Horizonte, 2010. Anais... Belo Horizonte: SBC, 2010. p. $1045-1054$.

TAVARES, M. J.; FERNANDES, I. R.; TAVARES, L. V. A cognição e as tecnologias: aprendizagem mediada pela interação. InterSciencePlace, v. 12, n. 1, p. 1-173 jan./mar. 2017.

TCHOUNIKINE, P. Computer science and educational software design: a resource for multidisciplinary work in Technology Enhanced Learning. New York: Springer, 2011.

TEPPO, A.; van den HEUVEL-PANHUIZEN, M. Visual representations as objects of analysis: the number line as an example. ZDM - The International Journal on Mathematics Education, v. 46, n. 1, p. 45-58, feb. 2014.

VALENTE, J. A. Por que o computador na educação? In: VALENTE, J. A. (Org.). Computadores e conhecimento: repensando a educação. Campinas: UNICAMP, 1993. p. 24-44.

VALENZUELA, S. T. F.; GRECCO, A. M. V.; SOUZA, S. R. O. O uso de softwares na prática pedagógica dos professores de matemática: relato de experiência. Revista de Educac口ão, v. 12, n. 13, p. 119-124, 2009.

WAY, J. Developing fraction sense using digital learning objects. In: WAY, J.; BOBIS, J. (Eds.). Fractions: teaching for understanding. Adelaide, SA: Australian Association of Mathematics Teachers, 2011. p. 153166.

WINARTI, D. W.; AMIN, S. M.; LUKITO, A.; van GALLEN, F. Learning the concept of area and perimeter by exploring their relation. Journal on Mathematics Education, v. 3, n. 1, p. 41-54, jan. 2012.

YAKES, C. Rational number operations on the number line. The Mathematics Enthusiast, v. 14, n. 1, p. 309-324, 2017.

YUSHAU, B.; BOKHARI, M. A.; WESSELS, D. C. J. Computer aided learning of mathematics: software evaluation. Mathematics and Computer Education, New York, v. 38, n. 2, p. 165-82, 2004.

ZAZKIS, R.; LILJEDAHL, P. Understanding primes: the role of representation. Journal for Research in Mathematics Education, Reston, v. 35, n. 3, p. 164-186, 2004.

ZÍLIO, C.; ALVES, E. Mapeamento dos recursos informatizados nas Escolas Estaduais de Porto Alegre. In: CONGRESSO INTERNACIONAL DE INFORMÁTICA EDUCATIVA, 8., 2013, Porto Alegre. Anais... Porto Alegre: PUCRS, 2013. p. 395-404. 
Recebido em agosto de 2018.

Aprovado para publicação em julho de 2019.

Aleandra da Silva Figueira-Sampaio

Faculdade de Gestão e Negócios - FAGEN, Universidade Federal de Uberlândia - UFU, Brasil, aleandra@ufu.br

\section{Eliane Elias Ferreira dos Santos}

Escola de Educação Básica - ESEBA, Universidade Federal de Uberlândia - UFU, Brasil, elianelias@yahoo.com.br

\section{Gilberto Arrantes Carrijo}

Faculdade de Engenharia Elétrica - FEELT, Universidade Federal de Uberlândia - UFU, Brasil, gilberto@ufu.br

\section{Quintiliano Siqueira Schroden Nomelini}

Faculdade de Matemática - FAMAT, Universidade Federal de Uberlândia - UFU, Brasil, quintiliano.nomelini@ufu.br 